Available online on 15.11.2017 at http://jddtonline.info
Journal of Drug Delivery and Therapeutics
Open Access to Pharmaceutical and Medical Research
$\begin{gathered}\text { 2011-17, publisher and licensee JDDT, This is an Open Access article which permits unrestricted non- } \\ \text { commercial use, provided the original work is properly cited }\end{gathered}$

Open Access

Research Article

\title{
FABRICATION AND OPTIMIZATION OF NOVEL GLIPIZIDE SUSTAINED RELEASE MATRICES FOR SOLUBILITY AND DISSOLUTION ENHANCEMENT BY SOLID DISPERSION THROUGH HYDROPHILLIC CARRIERS
}

\author{
Shende MA*, Fiske PV \\ Department of Pharmaceutics, Government College of Pharmacy, Kathora Naka, Amravati, 444604, India
}

\section{ABSTRACT}

The present research work was to improve the dissolution rate of glipizide which belongs to BCS II drug by enhancing its aqueous solubility using different hydrophilic carriers like PEG 6000 and hydroxylpropyl methylcellulose E15 (HPMC E15). The solid dispersion was embedded into the matrix of polymers to sustain the release pattern of drug. The various solid dispersion formulations were prepared by employing fusion method using different carriers. Further solid dispersion formulations were subjected to different in-vitro evaluation tests for solubility, drug content uniformity, drug-polymer interaction, DSC study and invitro drug release study. Tablets were prepared by direct compression method and evaluated for various physical parameters. A direct compression method using response surface methodology, followed by optimization of the evaluated parameters was employed to get the final optimized formulation. The results of drug content uniformity showed the uniform dispersion of glipizide in solid dispersion formulations. The DSC endothermic peak at $216.08^{\circ} \mathrm{C}$ due to glipizide was partially and completely disappeared in solid dispersion formulation indicating that drug was completely dispersed in formulations. In-vitro drug release showed $80.35 \%$ in 60 minutes for the best solid dispersion formulation S3 (ratio 1:3). Among all the formulations, F4 shows $92.87 \%$ better sustained release at the end of $12 \mathrm{hrs}$. The release co-efficient values ' $\mathrm{n}$ ' $(<0.5)$ indicated that the drug release followed fickian diffusion mechanism based on formulation factors. The stability studies were carried out according to ICH guideline and result found of selected formulation was stable.

Keywords: Glipizide, Solid dispersion, Xanthan gum, Matrices

Article Info: Received 18 Sep, 2017; Review Completed 29 Oct, 2017; Accepted 29 Oct, 2017; Available online 15 Nov, 2017

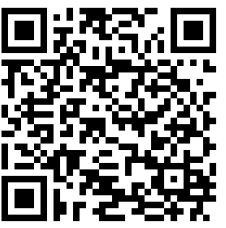

Cite this article as:

Shende MA, Fiske PV, Fabrication and optimization of novel glipizide sustained release matrices for solubility and dissolution enhancement by solid dispersion through hydrophillic carriers, Journal of Drug Delivery and Therapeutics. 2017; 7(6):38-48

DOI: http://dx.doi.org/10.22270/jddt.v7i6.1538

*Address for Correspondence

MA Shende, Department of Pharmaceutics, Government College of Pharmacy, Kathora Naka, Amravati, 444604, India. E-mail: shende_mulchand@rediff.com, Telephone: +917719919955

\section{INTRODUCTION}

Solid dispersion refers to a group of solid products consisting of at least two different compounds, a hydrophilic matrix and a hydrophobic drug. The drug can be dispersed molecularly, in amorphous particles or in crystalline particles. Pharmaceutical polymers are used to create this matrix and their selection is based on many factors, including physicochemical (drug polymer miscibility and stability) and pharmacokinetic (rate of absorption) constraints. ${ }^{1}$ In solid dispersions, a portion of drug dissolves immediately to saturate the gastrointestinal tract fluid, and excess drug precipitates as fine colloidal particles or oily globules of submicron size. The development of solid dispersions as a practically viable method to enhance bioavailability of poorly water-soluble drugs overcame the limitations of previous approaches such as salt formation, solubilization, co-solvency, and particle size reduction. ${ }^{2}$ An oral route of drug administration is the most preferred route of drug delivery due to convenience and ease of ingestion. A solid dosage form is a comfortable 
and familiar means of taking medication. Hence, a patient compliance and drug treatment is usually more effective with orally administered medications than other routes of administration. ${ }^{3}$ The poorly watersoluble drugs are increasingly becoming a problem in terms of obtaining the satisfactory dissolution within the gastrointestinal tract that is necessary for good bioavailability. Glipizide is an oral hypoglycemic agent, which is a commonly prescribed drug for the treatment of patients with type II diabetes. ${ }^{4}$ It is used adjunct to diet to the management of type II (non-insulin dependent) diabetes mellitus in patients whose hyperglycemia cannot be controlled by diet and exercise alone. Glipizide stimulates insulin secretion from the $\beta$ cells of pancreatic islets tissue, increases the concentration of insulin in the pancreatic vein and may increase the number of insulin receptors. Glipizide is a weak acid $(\mathrm{pKa}=5.9)$ practically insoluble in water and acidic environment and highly permeable (class II) drugs according to the Biopharmaceutical Classification System (BCS). ${ }^{5}$ Glipizide is an oral rapid and short acting antidiabetic drug from sulfonylurea class (figure $1)$.

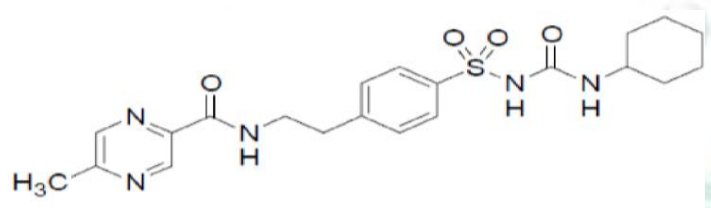

Figure 1: 1-cyclohexyl-3-[[p-[2-(5methylpyrazinecarboxamido) ethyl] phenyl] sulfonyl] urea

The oral absorption is uniform, rapid and complete with a bioavailability of nearly $100 \%$ and an elimination halflife of 2-4 hours. Glipizide is reported to have a short biological half-life $(3.4 \pm 0.7 \mathrm{~h})$ requiring it to be administered in 2 to 3 doses of 2.5 to $10 \mathrm{mg}$ per day. Sustained release formulations that would maintain plasma levels of drug for 8 to $12 \mathrm{hrs}$ might be sufficient for once a day dosing for glipizide. SR products are needed for glipizide to prolong its duration of action and to improve patient compliance. ${ }^{6}$ Therefore, there is need to formulate once daily controlled release tablet of glipizide which is convenient for older patients. ${ }^{7}$ The hydrophilic polymer selected for the present study was hydroxylpropyl methyl cellulose K100 (HPMC K100) and xanthan gum. Hydrophilic polymer matrix system are widely used for designing oral sustained release delivery systems because of their flexibility to provide a desirable drug release profile, cost effectiveness, and broad regulatory acceptance. HPMC K 100 forms transparent tough and flexible films from aqueous solution. ${ }^{8}$ So the aim of the proposed work was to improve the solubility and dissolution of poorly aqueous soluble drug of glipizide which belongs to BCS II using solid dispersion technique and to explore the design of controlled drug delivery system to prolong the drug release in gastrointestinal tract after oral administration.

\section{MATERIALS AND METHODS}

\section{Materials}

Glipizide was a gift sample from Jash Pharma Pvt. Ltd. Mumbai. Polyethylene glycol (PEG 6000), HPMC K-
100 and HPMC E15 was supplied from S.D. Fine Chemicals Limited, Mumbai. All the chemicals and reagents were used of AR Grade.

\section{Preparation of solid dispersion by fusion method}

The solid dispersion systems of glipizide were prepared with polyethylene glycol (PEG) and hydroxyl propyl methyl cellulose (HPMC E15) in 3 different ratios 1:1 (S1), 1:2 (S2) and 1:3 (S3) by employing fusion method. The accurately weighed amount of carrier was melted in a porcelain dish and calculated amount of glipizide was added with thorough mixing for 1-2 minutes followed by solidified rapidly in an ice-bath under vigorous stirring. The final solid mass is crushed, pulverized and sieved. $^{6,9}$

\section{Characterization and evaluation of solid dispersion}

\section{Solubility studies and drug content}

The solubility measurements of glipizide were carried out by adding excess amount of drug $(50 \mathrm{mg})$ to $20 \mathrm{ml}$ of HPMC E15 and PEG 6000 prepared in phosphate buffer of pH 7.4 in a series of stoppered conical flasks in the concentration of $2,4,6$ and $8 \%$. Later, the suspensions were agitated at $37^{\circ} \mathrm{C} \pm 1{ }^{\circ} \mathrm{C}$ until equilibrium was achieved. Then $1 \mathrm{ml}$ aliquots were filtered, diluted suitably and assayed by employing Shimadzu UV-Spectrophotometer at $275 \mathrm{~nm}$ for glipizide content. The data were compared with the solubility of solid dispersion S1, S2 and S3. The sample equivalent to $20 \mathrm{mg}$ of glipizide was accurately weighed and transferred to $50 \mathrm{ml}$ volumetric flask and extracted in phosphate buffer $\mathrm{pH} 7.4$ using the mechanical shaker. The volume was made up to $50 \mathrm{ml}$ with phosphate buffer $\mathrm{pH} 7.4$. From this $1 \mathrm{ml}$ is subsequently diluted to $10 \mathrm{ml}$ with phosphate buffer $\mathrm{pH} 7.4$ and assayed for glipizide content by measuring at $275 \mathrm{~nm}$ using phosphate buffer pH 7.4 as blank.

\section{FT-IR Spectroscopy}

The solid dispersion (S3) was characterized by FT-IR spectra by preparing $\mathrm{KBr}$ pellets at scanning range of $4000-400 \mathrm{~cm}^{-1}$ using a Shimadzu FT-IR spectrometer. ${ }^{10}$

\section{DSC study}

The physical state of drug in the samples was determined by Differential Scanning Calorimetry (DSC) using SDTQ 600 V 20.9 BUILD 20, Universal V4.5ATA instrument. Samples containing $3 \mathrm{mg}$ of drug were placed in the aluminum pans and heated from $10^{\circ} \mathrm{C}$ to $350^{\circ} \mathrm{C}$ at a heating rate of $10^{\circ} \mathrm{C} / \mathrm{min}$ under inert atmosphere flushed with nitrogen at the rate of 20 $\mathrm{ml} / \mathrm{min}^{11,12}$

\section{Drug dissolution test}

The in-vitro dissolution studies were performed for glipizide and all solid dispersion formulations using USP XXII dissolution test apparatus type II (Electro lab) maintained at $50 \mathrm{rpm}$. Glipizide pure drug $20 \mathrm{mg}$ and solid dispersions system equivalent to $20 \mathrm{mg}$ of glipizide were accurately weighed and used in each test. The dissolution studies were carried out using $900 \mathrm{ml}$ of phosphate buffer solutions ( $\mathrm{pH} 7.4$ ), maintained at $37 \pm$ $5^{\circ} \mathrm{C}$ was used as dissolution media to maintain the sink 
condition. The release of glipizide was measured by withdrawing $10 \mathrm{ml}$ aliquot samples at regular time intervals and withdrawn volume was replaced with fresh quantity of dissolution medium. ${ }^{7}, 13$ The withdrawn samples were filtered through whattman filter paper and suitably diluted with buffer assayed by using Shimadzu UV-Spectrophotometer at $275 \mathrm{~nm}$. The \% cumulative drug release after every time intervals was calculated and reported.

\section{Drug-excipients compatibility studies by Fourier Transform Infrared (FTIR)}

Pure drug (glipizide), physical mixtures and solid dispersion were examined by Fourier Transform Infrared (FT-IR) spectra using potassium bromide pellet method. The FTIR spectra were recorded from 4000 to $400 \mathrm{~cm}^{-1}$ in a FTIR Affinity-1(DRS-8000), Shimadzu Japan Spectrophotometer. ${ }^{6}$

\section{Formulation of sustained release matrix tablets of glipizide}

The tablets were prepared by direct compression method using Rimek Minipress rotary tablet machine to obtain the tablets of desired specifications. The solid dispersion/polymer mixture ratio prepared by homogenously mixing with various concentrations of polymers. The compositions of matrices are given in table 1. All the ingredients sufficient for a batch of 100 tablets were weighed and passed through the sieve 40
(420 mm) and mixed by geometric dilution method and finely mixed using polythene bag for proper mixing, then prior compression magnesium stearate and talc was added as lubricating agent and compressed using a 8 $\mathrm{mm}$ round concave punches in 10 station tablet punching machine.

\section{Factorial design}

The use of trial and error technique for the development of a new pharmaceutical formulation leads to a satisfactory formulation rather than an optimal one. The optimization techniques, on the basis of a few experiments and statistical analysis of the results can provide an efficient and economical method for the prediction of the optimal composition. Design Expert 7.1 software was used for determining influence of the factors on selected responses (table 1). Formulations were developed following $3^{2}$ factorial design after setting the individual excipients series of formulations mentioned in the table 2 and statistically evaluated the effects of two formulation variables viz., the concentration of HPMC K100 (X $\left.\mathrm{X}_{1}\right)$ and the concentration of xanthan gum $\left(\mathrm{X}_{2}\right)$ on tablet parameters. The high and low levels of each variable were coded as 1 and -1 , respectively and the mean value as zero. The dependent variables measured were $\%$ cumulative drug release at $1 \mathrm{hr}(\mathrm{Q} 1), \%$ cumulative drug release after 8 hrs (Q8) and half life of drug release $\left(\mathrm{t}_{1 / 2}\right)$.

Table 1: Level of independent variables for $3^{2}$ factorial designs

\begin{tabular}{|l|c|c|c|}
\hline \multirow{2}{*}{ Independent variables (two) } & \multicolumn{3}{c|}{ Levels (three) } \\
\cline { 2 - 4 } & Low $(-1)$ & Medium $(0)$ & High $(+1)$ \\
\hline Concentration of HPMC K100 $\left(\mathrm{X}_{1}\right)$ & 8 & 10 & 12 \\
\hline Concentration of Xanthan Gum $\left(\mathrm{X}_{2}\right)$ & 7 & 10 & 13 \\
\hline
\end{tabular}

Table 2: Formulation components for different batches as per $3^{2}$ factorial design

\begin{tabular}{|c|c|c|c|c|c|c|c|}
\hline \multirow{3}{*}{ Batch } & \multicolumn{7}{|c|}{ Composition (mg) } \\
\cline { 2 - 9 } & $\begin{array}{c}\text { Glipizide solid } \\
\text { dispersion }\end{array}$ & $\begin{array}{c}\text { HPMC } \\
\text { K100 }\end{array}$ & $\begin{array}{c}\text { Xanthan } \\
\text { gum }\end{array}$ & Lactose & $\begin{array}{c}\text { Microcrystalline } \\
\text { Cellulose }\end{array}$ & $\begin{array}{c}\text { Magnesium } \\
\text { Stearate }\end{array}$ & Talc \\
\hline F1 & 35 & 10 & 5.76 & 26.24 & 120 & 1 & 2 \\
\hline F2 & 35 & 10 & 10 & 22 & 120 & 1 & 2 \\
\hline F3 & 35 & 8 & 13 & 21 & 120 & 1 & 2 \\
\hline F4 & 35 & 8 & 7 & 27 & 120 & 1 & 2 \\
\hline F5 & 35 & 12 & 13 & 17 & 120 & 1 & 2 \\
\hline F6 & 35 & 12.83 & 10 & 19.17 & 120 & 1 & 2 \\
\hline F7 & 35 & 10 & 14.24 & 17.76 & 120 & 1 & 2 \\
\hline F8 & 35 & 7.17 & 10 & 24.83 & 120 & 1 & 2 \\
\hline F9 & 35 & 12 & 7 & 23 & 120 & 1 & 2 \\
\hline
\end{tabular}

Stepwise regression analysis was used to find out the control factors that significantly affect response variables. The results were subjected to ANOVA and multiple regression analysis that led to equations describing the effect of independent variables on the selected responses. The level of significance selected was $5 \%(\mathrm{P}<0.05)$. Contour plot and response surface plot were also conducted and studied. With the help of overlay plot best optimized formulation was found out by keeping the desired responses.

\section{Pre-compression parameters}

Pre-compression studies carried out of blend powder mixtures for flow properties, bulk density, tapped density, compressibility index and Hausner's ratio. ${ }^{12}$

\section{Post-compression parameters}

The formulated matrices were evaluated for thickness, hardness, friability, content uniformity, weight variation, matrix erosion, swelling index and in-vitro drug release. 


\section{Thickness and diameter}

Thickness of tablets was determined using Vernier caliper. Five tablets from each batch were used, and an average value was calculated. Tablet was selected random from individual formulation and thickness was measured. Tablet thickness should be controlled within a $\pm 5 \%$ variation of slandered value.

\section{Weight variation, hardness and friability}

Weight variation, friability test was conducted according to USP and the hardness was measured with Monsanto hardness tester. ${ }^{6,12}$

\section{Content uniformity}

Randomly ten tablets were weighed and powdered. A quantity equivalent to $20 \mathrm{mg}$ of glipizide was placed in $100 \mathrm{ml}$ volumetric flask and dissolved in phosphate buffer $\mathrm{pH} 7.4$ solutions, sonicated for 5 minutes and made up the volume up to the mark and filtered through membrane filter. After appropriate dilutions, the drug content was determined by UV spectrophotometer at 275 $\mathrm{nm}$ against suitable blank using standard plot equation. ${ }^{14}$

\section{In-vitro release study}

The in-vitro release study for all the formulations were carried out for $12 \mathrm{hrs}$ using a USP-Dissolution Test Apparatus Type-II (USP Dissolution Apparatus IP/USP, Veego Scientific DA6D, Mumbai) using $900 \mathrm{ml}$ of 7.4 $\mathrm{pH}$ phosphate buffer at $37 \pm 0.5^{\circ} \mathrm{C}$ with paddle rotation speed of $50 \mathrm{rpm}$. At predetermined intervals $10 \mathrm{ml}$ sample was withdrawn and equal volume was replaced to maintain sink condition. The sample was further diluted with corresponding media and absorbance measured in a UV spectrophotometer (Pharma Spec UV1700; Shimadzu, Japan) at $275 \mathrm{~nm}$ against suitable blank. The absorbance was converted to drug concentration using a calibration curve (Abs = $0.034 \times$ Conc $\left.+0.05 ; \mathrm{R}^{2}=0.993\right)$ and then cumulative $\%$ drug released was calculated with the help of dilution factor. ${ }^{14}$

\section{Analysis of in-vitro drug release kinetics and mechanism}

To describe the kinetics and \% releases of the drug release from sustain release matrix glipizide formulation.
The drug release data from factorial batches were fitted in to various kinetic release mathematical models such as zero order, first order, Higuchi, Korsmeyer-Peppas models by using PCP-Disso-v3 software. The regression coefficient $\left(\mathrm{r}^{2}\right)$ value compared to each other and selected best fit model, the release mechanism of glipizide from system were decided from release exponent value. The zero-order kinetic describes the system in which the drug release rate is independent of its concentration. The first order kinetic describes the system in which the drug release rate is concentration dependent. Higuchi describe the release of drug from an insoluble matrix as square root of time dependent process. The Hixon-Crowell cube root law describes the drug release from system in which there is change in the surface area and the diameter of particles present in dosage form. ${ }^{15,16}$

- Zero order Kinetics $\mathrm{Q}=\mathrm{K}_{0} \mathrm{t}$

- First order Kinetics $\log \mathrm{C}=\log \mathrm{C}_{0}-\mathrm{Kt} / 2$

- Higuchi's Square root of time Equation( Diffusion model) $\quad \mathrm{Q}=\mathrm{Kt}^{1 / 2}$

- Hixon-Crowell cube root Equation (Erosion model)

$$
(100-\mathrm{W})^{1 / 3}=100^{1 / 3}-\mathrm{k} 3 \mathrm{t}
$$

- Korsmeyer-Peppas model Equation (Diffusion/ Relaxation Model)

$$
\mathrm{Mt} / \mathrm{M}_{0}=\mathrm{k} 5 \mathrm{t}^{\mathrm{n}}
$$

\section{Stability Study}

The optimized formulation was subjected to stability at $40 \pm 2^{0} \mathrm{C}$ and $75 \pm 5 \% \mathrm{RH}$ for period of six months. After three and end of month tablet sample was analyzed for physical characteristics and drug release profile. ${ }^{17}$

\section{RESULT AND DISCUSSION}

Solubility of pure drug was determined in water which was then compared with the solubility of solid dispersion S1, S2 and S3. The effect of PEG 6000 and HPMC E15on the solubility of glipizide was studied and results summarized in table 3 .

Table 3: Solubility and drug content in solid dispersion of glipizide

\begin{tabular}{|c|c|c|c|c|}
\hline \multirow{2}{*}{ Formulation } & \multicolumn{2}{|c|}{ Solubility } & \multicolumn{2}{|c|}{ Drug content } \\
\cline { 2 - 5 } & Concentration (\%) & Solubility (mg/ml) & Concentration (mg/ml) & Drug Content (\%) \\
\hline \multirow{3}{*}{ Drug } & 1 & 0.23 & 0.025 & 4.41 \\
\cline { 2 - 5 } & 2 & 0.26 & 0.25 & 26.52 \\
\cline { 2 - 5 } & 3 & 0.29 & 0.5 & 47.26 \\
\hline \multirow{3}{*}{ S1 (1:1) } & 1 & 2.02 & 1.0 & 68.97 \\
\cline { 2 - 5 } & 2 & 3.52 & 0.025 & 28.79 \\
\hline \multirow{3}{*}{ S2 (1:2) } & 3 & 7.05 & 0.25 & 50.91 \\
\cline { 2 - 5 } & 1 & 4.08 & 0.5 & 88.52 \\
\hline \multirow{3}{*}{ S3 (1:3) } & 3 & 7.82 & 0.025 & 9.71 \\
\cline { 2 - 5 } & 1 & 11.26 & 0.25 & 30.47 \\
\cline { 2 - 5 } & 2 & 8.79 & 0.5 & 57.85 \\
\hline
\end{tabular}


The solubility studies showed that solubility of glipizide increased with concentrations of carrier. From the solubility and drug content analysis, sustained release solid dispersion (1:3) was selected for further studies. Fourier-transform infrared (FT-IR) spectroscopy was used to characterize possible interactions between the drug and the carrier in solid state. The IR spectra of solid dispersion and polymers used in solid dispersion are compared with the standard spectrum of glipizide. To study the possible interactions between glipizide, PEG 6000 and HPMC E15, FT-IR spectra of solid dispersions was compared with the drug alone. The FTIR spectra of glipizide exhibit characteristic peaks at $3352.64 \mathrm{~cm}^{-1}$ (NH stretching), $1482.99 \mathrm{~cm}^{-1} \quad(\mathrm{C}=\mathrm{O}$ stretching), $1649.8 \mathrm{~cm}^{-1}$ (NH bending), $1333.53 \mathrm{~cm}^{-1}$ (sulphonamide), $1307.5 \mathrm{~cm}^{-1}$ (aromatic), $1159.97 \mathrm{~cm}^{-1}$ (sulphone). In the FT-IR spectra of the best solid dispersion formulation $\mathrm{S} 3, \mathrm{C}=\mathrm{O}$ and $\mathrm{S}=\mathrm{O}$ stretching of sulphonyl group of the glipizide was shifted towards higher wavelength and the other peaks are almost the same (figure 2).

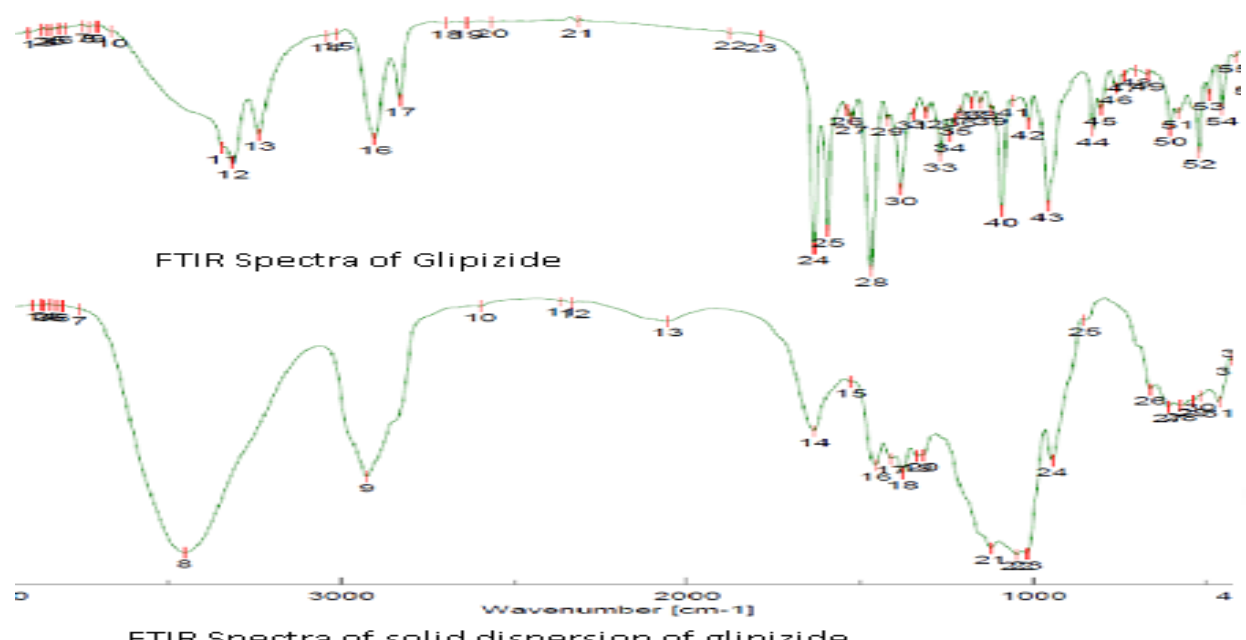

Figure 2: FTIR spectrum of glipizide and solid dispersion
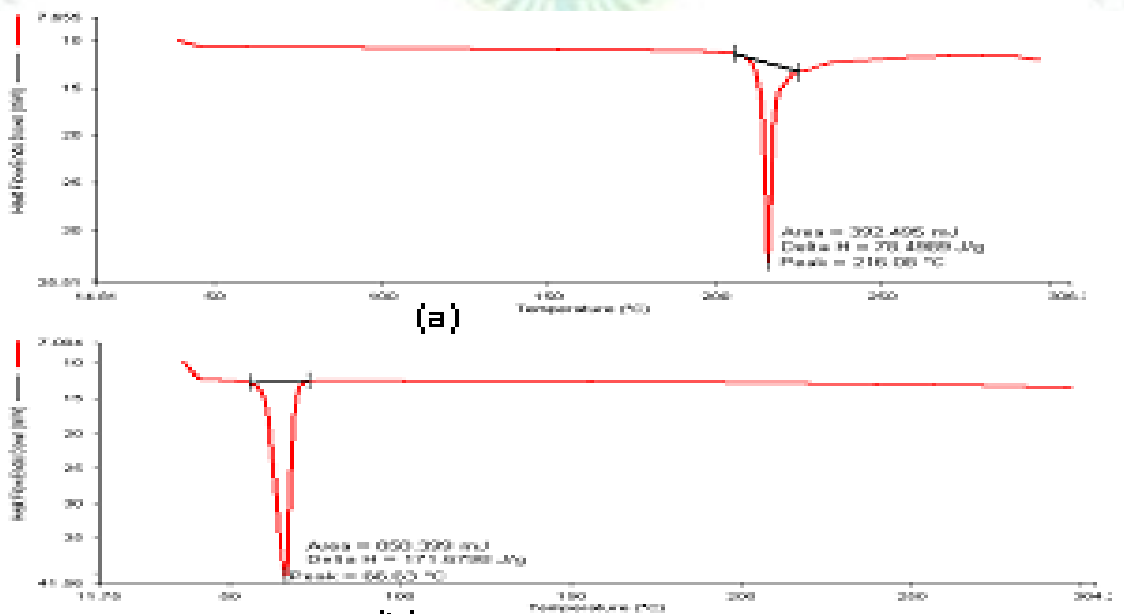

(b)
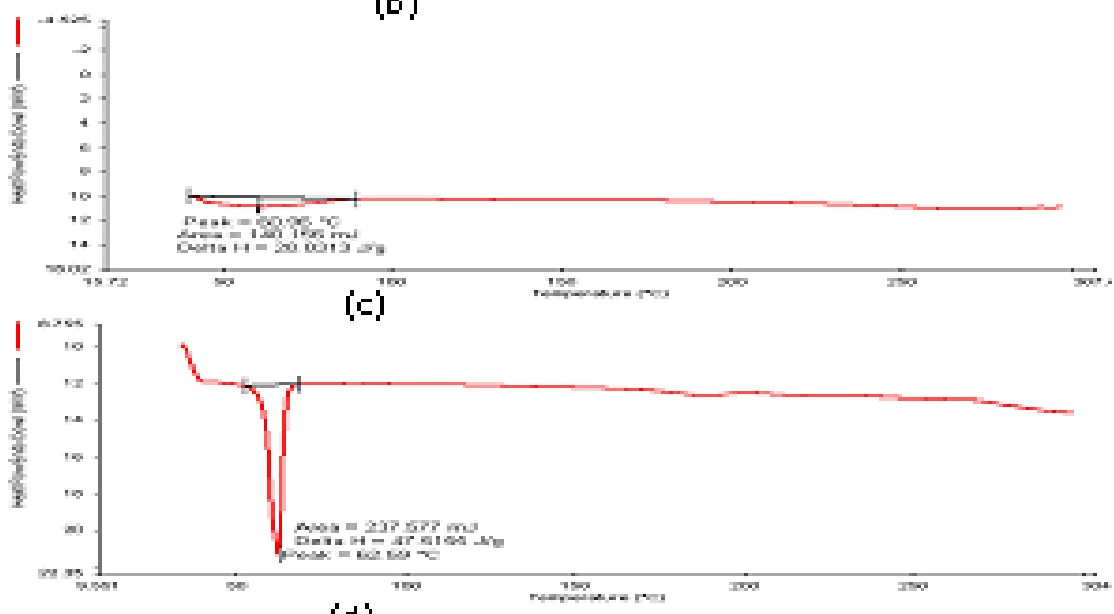

(d)

Figure 3: DSC Thermo grams of (a) glipizide, (b) PEG 6000, (c) HPMC E15, (d) Solid dispersion 
This indicated that overall symmetry of the molecule is not significantly affected. The shift in the peaks associated with the glipizide indicates an increase in bond strength, possibly due to the stabilizing effect of the hydrogen atoms of PEG or may be due to the intermolecular hydrogen bonding between glipizide and PEG in the solid state.

DSC studies were carried out for more confirmation for the difference in crystallinity of glipizide and DSC thermogram are shown in figure 3 . It showed that an endothermic peak of glipizide could be detected at about $216.08{ }^{\circ} \mathrm{C}$, PEG 6000 at $66.63{ }^{\circ} \mathrm{C}$, HPMC E15 at 60.96 and solid dispersion at $62.59{ }^{\circ} \mathrm{C}$. The best solid dispersion $\mathrm{S} 3$ in the ratio of $1: 3$ prepared using fusion method shows sharp endothermic peak at $60.96^{\circ} \mathrm{C}$ which could be due to the melting point of HPMC E15. The endothermic peak of glipizide is suppressed indicating glipizide would completely disperse in polymer. The disappearance of glipizide peak indicates decrease in crystallinity. This may explain the best enhancement of glipizide dissolution and hence confirms the formulation of solid dispersion.

\section{Drug-excipients interaction studies}

Fourier-transform infrared spectra were obtained by an FTIR-Affinity-1 spectrophotometer using the $\mathrm{KBr}$ disc method for determination of drug and polymer compatibility study. FTIR spectrum of pure glipizide showed characteristic peaks at $3352.64 \mathrm{~cm}^{-1}(\mathrm{NH}$ stretching), $1482.99 \mathrm{~cm}^{-1}$ ( $\mathrm{C}=\mathrm{O}$ stretching), $1649.8 \mathrm{~cm}^{-1}$ (NH bending), $1333.53 \mathrm{~cm}^{-1}$ (sulphonamide), 1307.5 $\mathrm{cm}^{-1}$ (aromatic), $1159.97 \mathrm{~cm}^{-1}$ (sulphone). In FTIR spectrum of HPMC K100, peaks were observed at 1240 $\mathrm{cm}^{-1}$ (ether) and $2922 \mathrm{~cm}^{-1}$ due to $\mathrm{CH}$ stretching. FTIR spectrum of PEG showed peaks at $1124 \mathrm{~cm}^{-1}$ (ether), $3450 \mathrm{~cm}^{-1}$ (OH stretching $\mathrm{H}$ bonded). FTIR spectrum of xanthan gum showed characteristic peaks at $3435 \mathrm{~cm}^{-1}$ (alcoholic $\mathrm{OH}$ stretching free), $2886 \mathrm{~cm}^{-1}$ for presence of alkane, $1690 \mathrm{~cm}^{-1}$ indicating the presence of unsaturated carboxylic acid. FTIR spectra of powder blend showed peaks at $1649 \mathrm{~cm}^{-1}$ (NH bending), 1333 $\mathrm{cm}^{-1}$ (sulphonamide), $1307 \mathrm{~cm}^{-1}$ (aromatic), $1240 \mathrm{~cm}^{-1}$ (ether), $1023 \mathrm{~cm}^{-1}$ (alcoholic $\mathrm{OH}$ bending), $1124 \mathrm{~cm}^{-1}$ (ether), $3435 \mathrm{~cm}^{-1}$ (alcoholic $\mathrm{OH}$ stretching free), 2886 $\mathrm{cm}^{-1}$ (alkane) and $1690 \mathrm{~cm}^{-1}$ (unsaturated carboxylic acid). From the results (figure 4) obtained from FTIR spectra it was concluded that spectrum of physical mixture of glipizide shows that all the bands of glipizide in physical mixtures were preserved and shows no interaction in physical mixtures.

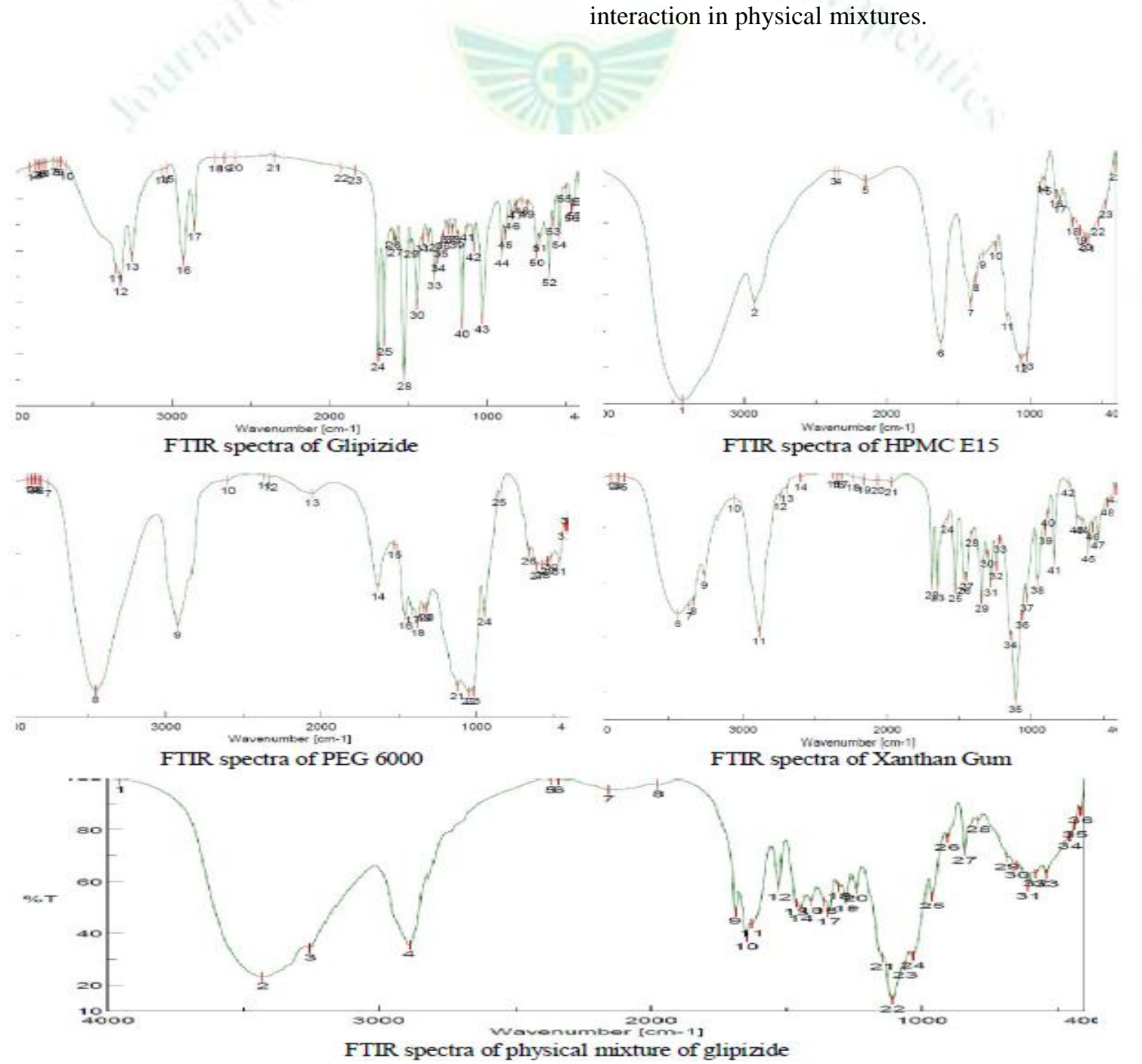

Figure 4: FT-IR spectrum for compatibility study of glipizide and polymers 
The bulk and tapped density of blend powder were found to be in the range of $0.31-0.33$ and $0.39-0.46$, respectively (table 4). Carr's compressibility index and hausner ratio are determined to be less than $16.83 \%$ and $<1.49$ for all formulations respectively, which indicates that the powder blend of all the formulations have fair to good flow property. The physical properties of tablets like hardness, friability, thickness, diameter, drug content and weight variation were found to be within limits indicating that the prepared matrix tablets met the USP specifications (table 5). The formulation showed hardness value in the range of to 5.8 to $7.16 \mathrm{Kg} / \mathrm{cm}^{2}$. The friability value for all tablet formulation were found to be less than $1 \%$ indicate that the friability within the prescribed limit.

Table 4: Pre-compression powder characteristics of F1-F9 batches

\begin{tabular}{|c|c|c|c|c|c|c|c|c|c|}
\hline Parameters & F1 & F2 & F3 & F4 & F5 & F6 & F7 & F8 & F9 \\
\hline Angle of repose & $23 \pm$ & $24 \pm$ & $23 \pm$ & $24 \pm$ & $22 \pm$ & $21 \pm$ & $22 \pm$ & $27 \pm$ & $21 \pm$ \\
& 1.852 & 1.331 & 1.537 & 2.961 & 1.321 & 1.525 & 1.532 & 1.862 & 1.267 \\
\hline Bulk density & $0.32 \pm$ & $0.31 \pm$ & $0.32 \pm$ & $0.31 \pm$ & $0.32 \pm$ & $0.33 \pm$ & $0.33 \pm$ & $0.32 \pm$ & $0.31 \pm$ \\
& 0.01 & 0.11 & 0.02 & 0.04 & 0.14 & 0.02 & 0.11 & 0.12 & 0.24 \\
& & & & & & & & & \\
\hline Tapped density & $0.44 \pm$ & $0.45 \pm$ & $0.39 \pm$ & $0.44 \pm$ & $0.42 \pm$ & $0.41 \pm$ & $0.46 \pm$ & $0.42 \pm$ & $0.46 \pm$ \\
& 0.023 & 0.008 & 0.004 & 0.009 & 0.006 & 0.043 & 0.004 & 0.005 & 0.011 \\
\hline Compressibility & $11.16 \pm$ & $11.57 \pm$ & $12.82 \pm$ & $10.68 \pm$ & $13 \pm$ & $12.99 \pm$ & $11.42 \pm$ & $14.19 \pm$ & $16.83 \pm$ \\
index & 1.24 & 1.41 & 1.22 & 1.22 & 1.03 & 1.51 & 1.64 & 1.54 & 1.60 \\
\hline Hausner's ratio & $1.13 \pm$ & $1.09 \pm$ & $1.13 \pm$ & $1.19 \pm$ & $1.16 \pm$ & $1.20 \pm$ & $1.14 \pm$ & $1.49 \pm$ & $1.11 \pm$ \\
& 0.06 & 0.03 & 0.04 & 0.07 & 0.05 & 0.02 & 0.01 & 0.06 & 0.03 \\
\hline
\end{tabular}

( \pm Standard deviation, $\mathrm{n}=3$ )

Table 5: In process quality control (IPQC) test for batches F1-F9

\begin{tabular}{|c|c|c|c|c|c|c|c|c|c|}
\hline Parameters & F1 & F2 & F3 & $\mathrm{F} 4$ & F5 & F6 & F7 & F8 & F9 \\
\hline $\begin{array}{l}\text { Hardness } \\
\left(\mathrm{Kg} / \mathrm{cm}^{2}\right)\end{array}$ & $\begin{array}{c}6.02 \pm \\
0.06\end{array}$ & $\begin{array}{c}5.80 \pm \\
0.45\end{array}$ & $\begin{array}{c}5.97 \pm \\
0.14\end{array}$ & $\begin{array}{c}6.89 \pm \\
0.11\end{array}$ & $\begin{array}{c}6.26 \pm \\
0.12\end{array}$ & $\begin{array}{c}7.16 \pm \\
0.37\end{array}$ & $\begin{array}{c}6.14 \pm \\
0.13\end{array}$ & $\begin{array}{c}5.76 \pm \\
0.27\end{array}$ & $\begin{array}{c}6.19 \pm \\
0.11\end{array}$ \\
\hline $\begin{array}{c}\text { Weight } \\
\text { uniformity }(\mathrm{mg})\end{array}$ & $\begin{array}{c}201 \pm \\
0.54\end{array}$ & $\begin{array}{c}194.9 \pm \\
0.13\end{array}$ & $\begin{array}{c}200 \pm \\
0.78\end{array}$ & $\begin{array}{c}202 \pm \\
0.13\end{array}$ & $\begin{array}{c}196 \pm \\
0.14\end{array}$ & $\begin{array}{c}204 \pm \\
0.37\end{array}$ & $\begin{array}{c}200 \pm \\
0.59\end{array}$ & $\begin{array}{c}191 \pm \\
0.5\end{array}$ & $\begin{array}{c}190 \pm \\
0.14\end{array}$ \\
\hline Diameter (mm) & $\begin{array}{c}8.02 \pm \\
0.01\end{array}$ & $\begin{array}{l}8.02 \pm \\
0.03\end{array}$ & $\begin{array}{c}8.01 \pm \\
0.06\end{array}$ & $\begin{array}{c}8.02 \pm \\
0.02\end{array}$ & $\begin{array}{c}8.01 \pm \\
0.03\end{array}$ & $\begin{array}{c}8.01 \pm \\
0.02\end{array}$ & $\begin{array}{c}8.03 \pm \\
0.01\end{array}$ & $\begin{array}{l}8.01 \pm \\
0.05\end{array}$ & $\begin{array}{c}8.04 \pm \\
0.04\end{array}$ \\
\hline Thickness (mm) & $\begin{array}{c}2.30 \pm \\
0.01\end{array}$ & $\begin{array}{c}2.30 \pm \\
0.01\end{array}$ & $\begin{array}{c}2.32 \pm \\
0.01\end{array}$ & $\begin{array}{c}2.32 \pm \\
0.03\end{array}$ & $\begin{array}{c}2.12 \pm \\
0.03\end{array}$ & $\begin{array}{c}2.33 \pm \\
0.01\end{array}$ & $\begin{array}{c}2.31 \pm \\
0.01\end{array}$ & $\begin{array}{c}2.21 \pm \\
0.01\end{array}$ & $\begin{array}{c}2.33 \pm \\
0.01\end{array}$ \\
\hline Friability (\%) & $\begin{array}{c}0.79 \pm \\
0.09\end{array}$ & $\begin{array}{c}0.61 \pm \\
0.21\end{array}$ & $\begin{array}{c}0.77 \pm \\
0.10\end{array}$ & $\begin{array}{c}0.75 \pm \\
0.04\end{array}$ & $\begin{array}{c}0.53 \pm \\
0.08\end{array}$ & $\begin{array}{c}0.72 \pm \\
0.1\end{array}$ & $\begin{array}{c}0.58 \pm \\
0.02\end{array}$ & $\begin{array}{c}0.68 \pm \\
0.25\end{array}$ & $\begin{array}{c}0.62 \pm \\
0.16\end{array}$ \\
\hline $\begin{array}{c}\text { Drug Content } \\
\text { Uniformity (\%) }\end{array}$ & $\begin{array}{c}103.9 \pm \\
1.47\end{array}$ & $\begin{array}{c}99.5 \pm \\
2.14\end{array}$ & $\begin{array}{r}103.6 \\
\pm 0.14\end{array}$ & $\begin{array}{c}98.5 \pm \\
1.32\end{array}$ & $\begin{array}{c}101 \pm \\
1.32\end{array}$ & $\begin{array}{c}103 \pm \\
2.58\end{array}$ & $\begin{array}{l}98 \pm \\
0.11\end{array}$ & $\begin{array}{c}101.3 \pm \\
2.12\end{array}$ & $\begin{array}{c}101.0 \pm \\
2.17\end{array}$ \\
\hline
\end{tabular}

The pharmacopoeial limits of deviation for tablets of $200 \mathrm{mg}$ are $\pm 7.5 \%$ i.e. $\pm 11.25 \mathrm{mg}$. The average percentage deviation for all tablet formulation was found to be within the specified limits and hence all formulation complied with the test for uniformity of weight. Uniformity of all drug content was found within and among the ranged from $100.5 \%$ to $103.6 \%$. Invitro dissolution studies of solid dispersions were compared with the pure glipizide. It was found that the drug dissolution was highest i.e., $85.35 \%$ in the formulation S3 (drug and carrier ratio was 1:3 prepared by employing fusion method at the end of 60 minutes. Formulations containing solid dispersion in combination with XNG and HPMC K100 were compared to explore the effect of polymers and the amount of the drug release. The glipizide was released about $100 \%$ within 8 hrs from batches F5 to F9. Percent of drug release at the end of $10 \mathrm{hrs}$ for F1, F2, F3, F5 and F6 were
$90.05 \pm 0.3 \%, 99.18 \pm 0.3 \%, 96.43 \pm 0.4 \%, 93.55 \pm 0.13 \%$ and $97.80 \pm 0.3 \%$ respectively. In the matrices formulation, HPMC K100 and XNG were used as prolonged and retard release polymer. These polymers produce gel-forming matrices and in contact with gastric fluid, possess sufficient structure to form a gel layer. The release pattern of all formulation is depicted in figure 5 .

The all factorial formulation batches were subjected to various release models, by using PCP-Disso-V3 Software. The four batches F1, F2, F6 and F9 showed Hixon Crowell as best fit model. F3, F4, F5 and F7 showed Korsmeyer- Peppas as best fit model and only F8 showed Quadratic Model as best fit model. By using Korsmeyer - Peppas equation, the value $\mathrm{n}$ was obtained. This value is characteristics of Anomalous kinetics (non fickian transport) for F1, F7, F8 and characteristics of fickian diffusion for F2, F3, F4, F5 (table 6). 


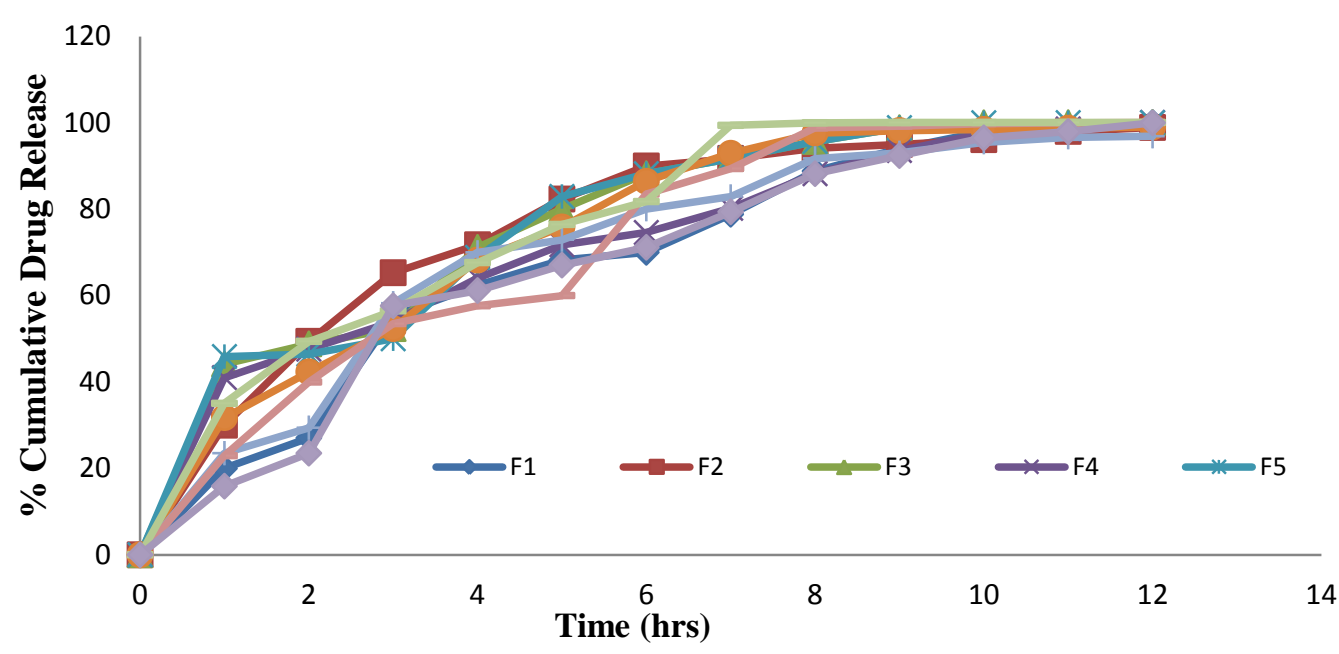

Figure 5: Dissolution studies of matrix formulation

\section{Statistical formulation optimization by $3^{2}$ factorial design}

It was observed that $\%$ drug release after 1 hour and after 8 hours ranging from $20 \%$ to $45 \%, 88 \%$ to $100 \%$ respectively and half life of drug release $\left(t_{50}\right)$ ranging from $5 \mathrm{hrs}$ to $10 \mathrm{hrs}$. The wide variation indicated that the physical properties of glipizide tablets were significantly influenced by the combinations of independent variables (table 7).

Table 6: Model fitting of factorial batches

\begin{tabular}{|c|c|c|c|c|c|c|}
\hline \multirow{2}{*}{ Code } & $\begin{array}{c}\text { Higuchi } \\
\text { Model }\end{array}$ & $\begin{array}{c}\text { Hixon- Crowell } \\
\text { Model }\end{array}$ & $\begin{array}{c}\text { Quadratic } \\
\text { Model }\end{array}$ & \multicolumn{2}{|c|}{$\begin{array}{c}\text { Korsmeyer Peppas } \\
\text { Model }\end{array}$} & \multirow{2}{*}{ Release } \\
\cline { 2 - 6 } & $\mathrm{R}$ & $\mathrm{R}$ & $\mathrm{R}$ & $\mathrm{R}$ & $\begin{array}{c}\text { Exponent(n) } \\
\text { Best fit model }\end{array}$ \\
\hline F1 & 0.9862 & 0.9921 & 0.9912 & 0.9870 & 0.572 & Hixon- Crowell \\
\hline F2 & 0.9729 & 0.9973 & 0.9869 & 0.9828 & 0.381 & Hixon- Crowell \\
\hline F3 & 0.9789 & 0.9822 & 0.9783 & 0.9862 & 0.385 & Korsmeyer- Peppas \\
\hline F4 & 0.9938 & 0.9786 & 0.9726 & 0.9967 & 0.415 & Korsmeyer- Peppas \\
\hline F5 & 0.9746 & 0.9777 & 0.9750 & 0.9808 & 0.391 & Korsmeyer - Peppas \\
\hline F6 & 0.9821 & 0.9956 & 0.9946 & 0.9840 & 0.449 & Hixon- Crowell \\
\hline F7 & 0.8390 & 0.8317 & 0.8315 & 0.8404 & 0.571 & Korsmeyer- Peppas \\
\hline F8 & 0.9815 & 0.9888 & 0.9905 & 0.9816 & 0.539 & Quadratic \\
\hline F9 & 0.9805 & 0.9888 & 0.9876 & 0.9844 & 0420 & Hixon- Crowell \\
\hline
\end{tabular}

Table 7: Effect of factors on responses variables of glipizide matrices

\begin{tabular}{|c|c|c|c|c|c|}
\hline \multirow{2}{*}{ Formulation code } & $\mathrm{X}_{1}$ & $\mathrm{X}_{2}$ & $\mathrm{Y}_{1}$ & $\mathrm{Y}_{2}$ & $\mathrm{Y}_{3}$ \\
\cline { 2 - 6 } & $\begin{array}{c}\text { Conc. of } \\
\text { HPMC K100 }\end{array}$ & $\begin{array}{c}\text { Conc. of } \\
\text { Xanthan Gum }\end{array}$ & $\begin{array}{c}\text { \% cumulative drug } \\
\text { release at 1 hr (Q1) }\end{array}$ & $\begin{array}{c}\text { \% cumulative drug } \\
\text { release after 8 hrs (Q8) }\end{array}$ & $\mathrm{t}_{50}$ \\
\hline F1 & 10 & 5.76 & 20 & 88.82 & 5.17 \\
\hline F2 & 10 & 10 & 30 & 94.11 & 7 \\
\hline F3 & 8 & 13 & 44.17 & 95.68 & 10.19 \\
\hline F4 & 8 & 7 & 41 & 98.20 & 10.82 \\
\hline F5 & 12 & 13 & 45.88 & 97.68 & 7.37 \\
\hline F6 & 12.83 & 10 & 31.76 & 91.76 & 5.92 \\
\hline F7 & 10 & 14.24 & 23.52 & 98.82 & 5.68 \\
\hline F8 & 7.17 & 10 & 22.94 & 100.01 & 8.45 \\
\hline F9 & 12 & 7 & 37.05 & & \\
\hline
\end{tabular}

ANOVA for model with responses using $5 \%$ significance level is represented in table 8 . From the results, it can be concluded that for all three responses, the cross-product (interaction $\mathrm{X}_{1} \mathrm{X}_{2}$ ) effect and quadratic effect $\left(\mathrm{X}_{1}^{2}, \mathrm{X}_{2}^{2}\right)$ are not significant. But the linear $\left(\mathrm{X}_{1^{-}}\right.$
HPMC K100, $\mathrm{X}_{2}$-XG) model terms are significant. The polynomial equation contains coefficient for intercept, regression coefficients, individual effects $\left(\mathrm{X}_{1}\right.$ and $\left.\mathrm{X}_{2}\right)$; quadratic effects $\left(\mathrm{X}_{1}^{2}\right.$ and $\left.\mathrm{X}_{2}^{2}\right)$; the interaction effect $\left(X_{1} X_{2}\right)$. The sign and magnitude of the main effects 
signify the relative influence of each factor on the responses (table 8). The equation in terms of coded factors can be used to make predictions about the response for given levels of each factor. By default, the high levels of the factors are coded as +1 and the low levels of the factors are coded as -1 . The coded equation is useful for identifying the relative impact of the factors by comparing the factor coefficients. The equation in terms of actual factors can be used to make predictions about the response for given levels of each factor. This equation should not be used to determine the relative impact of each factor, because the coefficients are scaled to accommodate the units of each factor and the intercept is not at the center of the design space.

$$
\begin{aligned}
& \text { \% cumulative drug release at } 1 \mathrm{hr}\left(\mathrm{Y}_{1}\right)=1.84+0.117 \mathrm{X}_{1}+0.684 \mathrm{X}_{2}-0.025 \mathrm{X}_{1} \mathrm{X}_{2}+0.15 \mathrm{X}_{1}^{2}+0.45 \mathrm{X}_{2}^{2} \\
& \% \text { cumulative drug release after } 8 \mathrm{hrs}\left(\mathrm{Y}_{2}\right)=5.52+0.54 \mathrm{X}_{1}+1.07 \mathrm{X}_{2}+0.15 \mathrm{X}_{1} \mathrm{X}_{2}+0.44 \mathrm{X}_{1}^{2}-0.17 \mathrm{X}_{2}^{2} \\
& \qquad \mathrm{t}_{50}\left(\mathrm{Y}_{3}\right)=10.83+1.07 \mathrm{X}_{1}+2.37 \mathrm{X}_{2}-0.5 \mathrm{X}_{1} \mathrm{X}_{2}+0.77 \mathrm{X}_{1}^{2}+0.067 \mathrm{X}^{2}
\end{aligned}
$$

Table 8: ANOVA for model with responses

\begin{tabular}{|c|c|c|c|c|c|c|}
\hline \multirow{2}{*}{ Source } & \multicolumn{2}{|c|}{$\mathrm{Y}_{1}$} & \multicolumn{2}{c|}{$\mathrm{Y}_{2}$} & \multicolumn{2}{c|}{$\mathrm{Y}_{3}$} \\
\cline { 2 - 8 } & $\begin{array}{c}\mathrm{F} \\
\text { Value }\end{array}$ & $\begin{array}{c}\mathrm{p} \text {-value } \\
\text { Prob> F }\end{array}$ & $\begin{array}{c}\mathrm{F} \\
\text { Value }\end{array}$ & $\begin{array}{c}\mathrm{p} \text {-value } \\
\text { Prob> F }\end{array}$ & $\begin{array}{c}\mathrm{F} \\
\text { Value }\end{array}$ & $\begin{array}{c}\mathrm{p} \text {-value } \\
\text { Prob> F }\end{array}$ \\
\hline Model & 40.41 & 0.00593 & 20.34 & 0.017 & 20.058 & 0.017 \\
\hline A-HPMC K100 & 38.083 & 0.0086 & 16.29 & 0.028 & 8.64 & 0.061 \\
\hline B-Xanthan Gum & 152.34 & 0.00115 & 80.16 & 0.00294 & 86.76 & 0.0027 \\
\hline AB & 2.0083 & 0.252 & 2.386 & 0.23 & 0.598 & 0.496 \\
\hline $\mathrm{A}^{2}$ & 8.39 & 0.063 & 2.81 & 0.193 & 0.482 & 0.538 \\
\hline $\mathrm{B}^{2}$ & 1.24 & 0.347 & 0.022 & 0.894 & 3.825 & 0.146 \\
\hline
\end{tabular}

Figure 6 and 7 shows linear correlation between actual and predicted values for $\%$ cumulative drug release at 1 $\mathrm{hr}$ and $\%$ cumulative drug release after $8 \mathrm{hrs}$ respectively. From this graph we can conclude that factorial design used for optimization was valid with some error in predicted and actual values. Contour Plot for the relationship between amount of HPMC K100 and xanthan gum on $\mathrm{t}_{50}$ shows non-linear effect of amount of polymer HPMC K100 and xanthan gum (figure 8). The results showed that as the concentration of HPMC K100 and xanthan gum increases, \% drug release decreases showing controlled release of drug from the prepared formulation while polymer concentration increases, half life $\left(\mathrm{t}_{50}\right)$ of drug increases.

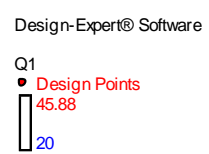

$X 1=A:$ conc of $H P M C$ $X 1=A:$ conc of $H P M C$
$X 2=B$ : Conc of $X G$

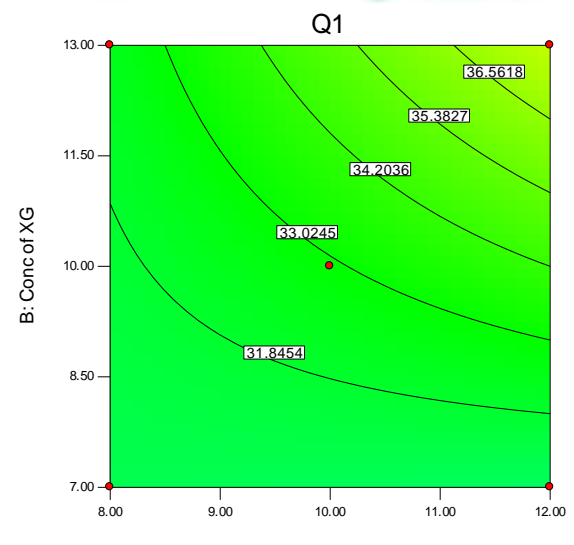

A: conc of HPMC

Figure 6: Contour Plot for the relationship between amount of HPMC K100 and xanthan gum on \% cumulative drug release at $1 \mathrm{hr}\left(\mathrm{Y}_{1}\right)$
Design-Expert@ Software

Q8
: Design Points
$\prod^{100.58}$

$\prod_{88.2}^{100 .}$

$\mathrm{X} 1=\mathrm{A}:$ conc of $\mathrm{HPMC}$
$\mathrm{X} 2=\mathrm{B}:$ Conc of $\mathrm{XG}$

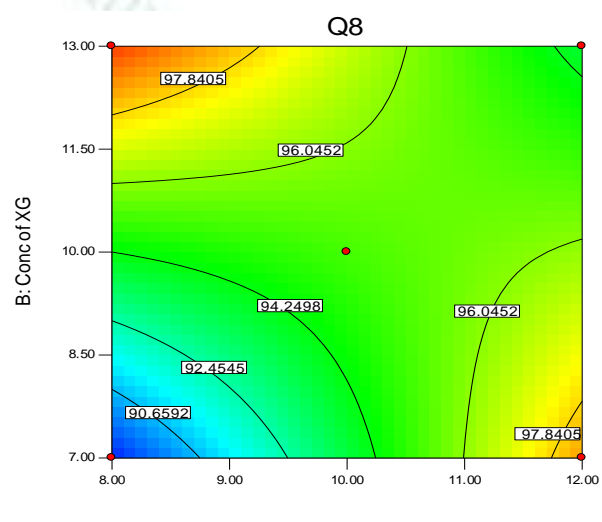

A: conc of HPMC

Figure 7: Contour Plot for the relationship between amount of HPMC K100 and xanthan gum on \% cumulative drug release after $8 \mathrm{hrs}\left(\mathrm{Y}_{2}\right)$
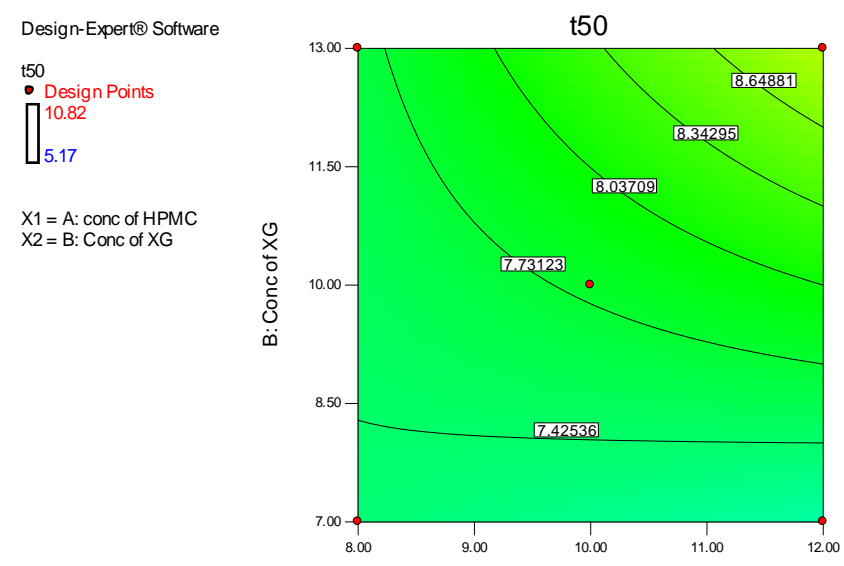

A: conc of HPMC

Figure 8: Contour Plot for the relationship between amount of HPMC K100 and xanthan gum on $\mathrm{t}_{50}\left(\mathrm{Y}_{3}\right)$ 
The formulation with an appropriate controlled release profile and $90 \%$ drug release over a 6-12 hours period was desired for the purpose of this study. Therefore, formulation F4 was considered most suitable and found desired region during optimization by overlay plot for the extended matrices. The extended retardation of drug release observed with xanthan gum may be attributed to the three dimensional gel network structure developed by polymer following penetration of dissolution medium into the tablet matrix. An incorporation of xanthan gum along with HPMC K100 decreased the release rate of drug because the polymer absorbs water and forms a gelatinous barrier layer at the surface of the tablet matrix. Usually, water diffusivity depends on the total concentration of viscosity-inducing agents in a system and this governs diffusion of water into matrix systems. ${ }^{18}$ The optimized F4 formulation showed good controlled release for longer time periods, good physical properties of matrices, Korsmeyer- Peppas as best fit model with 0.415 release exponent for fickian diffusion mechanism than the other formulations (figure 9). The simplicity of the formulation, ease of manufacturing and complete dissolution of drug from system is among the advantages of the developed matrix formulations. The results of release studies indicated the possibility of achieving a suitable modulation of matrix release rate by opportunely varying ratio of matrix tablets.

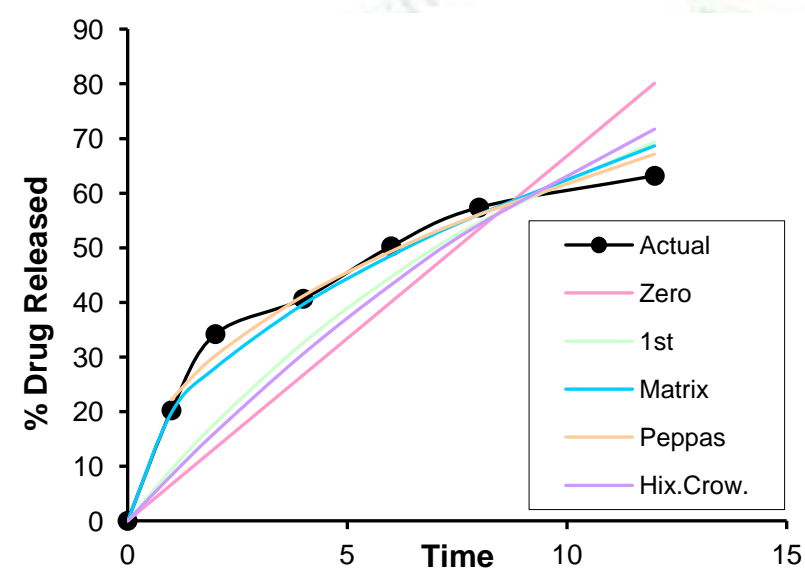

Figure 9: Model fitting of release profile for optimized F4 formulation
Statistical analysis of the results, before and after conducting the stability studies for 6 months, was carried out using paired students t-test. No significant difference (p> 0.05) was observed in the tablet appearance, hardness or thickness. The drug dissolution profile was compared of before and after stability studies. The optimized formulation $(\mathrm{F} 4)$ values were found more than 50 (91.26 and 90.15 respectively after one and three months) that indicate a good similarity between both the dissolution profiles. Similarly, no significant difference was observed in the post formulation parameter. The stability studies showed that there was no significant change in dissolution profile after storage.

\section{CONCLUSION}

With findings of research, it would be noticed that PEG 6000 and HPMC E15 in the best solid dispersion S3 has characteristics to form molecular dispersions with the drug molecules, hence enhancing the dissolution rate of drug and decreasing the time of drug release from the solid dispersion. The glipizide sustained release formulation (F4) with HPMC K100 (8 mg) and xanthan gum $(7 \mathrm{mg})$ showed good controlled release for longer time periods, good physical properties of matrices and exhibited less percentage deviation of response parameters from both predicted and target responses in comparison to other predicted formulations. The mechanism of release of glipizide from matrices was following Korsmeyer-Peppas as well as fickian diffusion. The results of stability studies for formulations F4 revealed no change in physical appearance, hardness and drug indicating the formulation was stable. From the present study, it can be concluded that glipizide matrices could be developed with desirable release modulation by solid dispersion sustained release matrix tablets for a once daily administration.

\section{ACKNOWLEDGEMENT}

Authors are thankful to Jash Pharma Pvt. Ltd., Mumbai for donating gift sample of glipizide and to the Principal, Government College of Pharmacy providing necessary facilities to carry out this work. 


\section{REFERENCES}

1. Parve B, Teli B, Birande A, Solid dispersions: An overview on solubility enhancement of poorly water soluble drugs, Int $\mathbf{J}$ Pharm Bio Sci, 2014; 5(3):7-25.

2. Patil PD, Bakliwal SR, Gujarathi NA, Rane BR, Pawar SP, Kapoor B, Solid dispersion: an evolutionary approach for solubility enhancement of poorly water soluble drugs, Pharma Science Monitor, 2013; 4(1):3683-3709.

3. Bhirud Y, Phalak H. Advances in solid dispersion technology and its applications in the development of solid dosage forms. Journal of Drug Delivery and Therapeutics, 2016; 6(6):40-47. doi:10.22270/jddt.v6i6.1316.

4. Jamzad S, Fassihi R, Development of controlled release low dose class II drug-glipizide, Int J Pharm, 2006; 312:24-32.

5. Dalvi P, Gerange A, Ingale P, Solid dispersion: strategy to enhance solubility. Journal of Drug Delivery and Therapeutics, 2015; 5(2):20-28. doi:10.22270/jddt.v5i2.1060

6. Pahwa R, Bohra P, Sharma PC, Kumar V, Dureja H, Glipizide: some analytical, clinical and therapeutic vistas, Int. J. Chem. Sci., 2010; 8(1):59-80.

7. Patel JK, Patel RP, Amin AF, Patel MM, Formulation and evaluation of glipizide microspheres, AAPS Pharm Sci Tech, 2005; 6:49-55.

8. Rodriguez L, Caputo O, Cini M, Cavallari C, Grecchi R, Invitro release of theophylline from directly-compressed matrices containing methacrylic acid copolymers and/or dicalcium phosphate dehydrate, Ill Farmaco, 1993; 48:1597604.

9. Sareen S, George M, Lincy J, Improvement in solubility of poor water-soluble drugs by solid dispersion, Int J Pharm Investig, 2012; 2(1):12-17.

10. Raymond CR, Paul JS, Paul JW, Ray R, Paul S, Hand book of pharmaceutical excipients. (4th edn), Science and Practice,
Royal Pharmaceutical Society of Great Britain, London, 2003; UK 447-450.

11. Frizon F, Eloy J, Donaduzzi C, Dissolution rate enhancement of loratadine in polyvinylpyrrolidone K-30 solid dispersion by solvent methods. Powder Technology, 2013; 235:532-539.

12. Lachman L, Lieberman HA, Kanig JL. The theory and practice of industrial pharmacy. 3rd ed. Mumbai: Varghese Publishing House; 1991. P. 297-300.

13. Sareen S, George M, Lincy J, Improvement in solubility of poor water-soluble drugs by solid dispersion, Int J Pharm Investig, 2012; 2(1):12-17.

14. Shaikh K, Dissolution and stability enhancement of poorly water soluble drug - lovastatin by preparing solid dispersions, Asian Journal of Biomedical and Pharmaceutical Sciences, 2011; 1(4):24-31.

15. Hindustan AA, Sreeramula J, Hima Bindu V, Kumar CS , A formulation and evaluation of once daily sustained release aceclofenac prosophis juliflora gum matrix tablets, International Journal of Pharmaceutical Sciences Review and Research, 2010; 1(2):23-28.

16. Shanker G, Kumar CK, Gonugunta CS, Kumar BV, Veera reddy PR, Formulation and evaluation of bioadhesive buccal drug delivery of tizanidine hydrochloride tablets, AAPS Pharm Sci Tech, 2009; 10(2):530-539.

17. Liu Q, Fassihi R, Zero order delivery of highly soluble, low dose drug alfuzosin hydrochloride via gastro retentive system", International Journal of Pharmaceutics, 2008; 348(12):27-34.

18. Radhika PR, Pal TK, Sivakumar T, Formulation and evaluation of sustained release matrix tablets of glipizide, Iranian Journal of Pharmaceutical Sciences, 2009; 5(4):205214. 